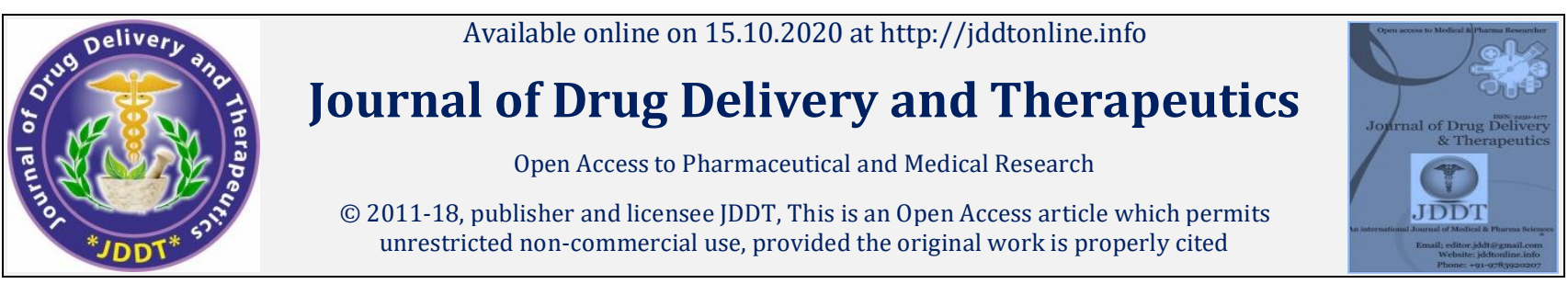

Open 1 Access

Research Article

\title{
Optimization of Process Parameters for Formulation of Fluvastatin Tablet by Using Dry Granulation Method
}

\author{
Nikhil Arun Shete ${ }^{*}$, Vishwajeet Swami ${ }^{2}$, Vaibhav Kulkarni' ${ }^{3}$, Gajanan Paratkar ${ }^{3}$, Rahul Mohan ${ }^{1}$ \\ ${ }^{1}$ Shri Sai College of Pharmacy, Khandala, India \\ 2 RJSPM'S institute of pharmacy, Pune, India \\ 3 Indira College of Pharmacy, Pune, India
}

\begin{abstract}
The manufacturing process of the tablet is a very complex process; it can be affected by the several process parameters or variables. The aim of this study was to understand and optimize the process parameters such as mixing, granulation, lubrication and tablets compres sion processes using quality by design (QbD) approach for a model Anti- Hyperlipidemic drug Fluvastatin sodium. During the processes there are several parameters which may influence or affect product quality. So the main objective of present work was to identify various process parameters and optimize this parameter, for the formulation of good quality product which needs to optimize Blending time, Roller force, Compression force and machine speed. A scale up batch was taken to evaluate and optimize the parameters. Critical quality attributes (CQA) such as flow behavior, granules parameters, Blend uniformity, tablet appearance, effect on tablet quality like physical appearance (surface, weight etc.) and tablet dissolution time as well as drug release. The test results of following parameters at various in-process phases are complies with the specified limits and finished product sample results were found to be within specified limits. This study results assures the manufacturing process is reproducible, robust and will yield consistent product, which meets specification.
\end{abstract}

Keywords: Process Parameters, Quality by Design, Fluvastatin, Granulation, Blending, Compression etc,.

Article Info: Received 19 July 2020; $\quad$ Review Completed 05 Sep 2020; $\quad$ Accepted 11 Sep 2020; Available online 15 Oct 2020

Cite this article as:

Shete NA, Swami V, Kulkarni V, Paratkar G, Mohan R, Optimization of Process Parameters for Formulation of Fluvastatin Tablet by Using Dry Granulation Method, Journal of Drug Delivery and Therapeutics. 2020; 10(5-s):97-107

http://dx.doi.org/10.22270/jddt.v10i5-s.4347

*Address for Correspondence:

Nikhil Arun Shete, Shri Sai College of Pharmacy, Khandala, India

\section{INTRODUCTION:}

Quality by Design (QbD): Recently proposed quality-bydesign $(\mathrm{QbD})$ regulatory initiative of pharmaceutical product and process development has encouraged researchers in pharmaceutical industry to reach the "desired state" of drug manufacturing in 21st century. Main goal of this approach is to gain a comprehensive understanding of their manufacturing processes, with an accurate estimation of their robustness and reliability.

The emphasis has changed from the need to demonstrate that the product will consistently meet relatively tight specifications to a new situation of being able to demonstrate that the product is controlled within a broader "design space" (DS). The design space (DS) concept is introduced as "the multidimensional combination and interaction of input variables (e.g., materials attributes) and process parameters that have been demonstrated to provide assurance of quality."

Using this approach, it is essential to define relationship between critical formulation/process parameters and critical quality attributes (such as granule characteristics and tablet properties. A simplified quality assurance diagram under the $\mathrm{QbD}$ for drug product development is schematically represented in Fig. 1.1,2 


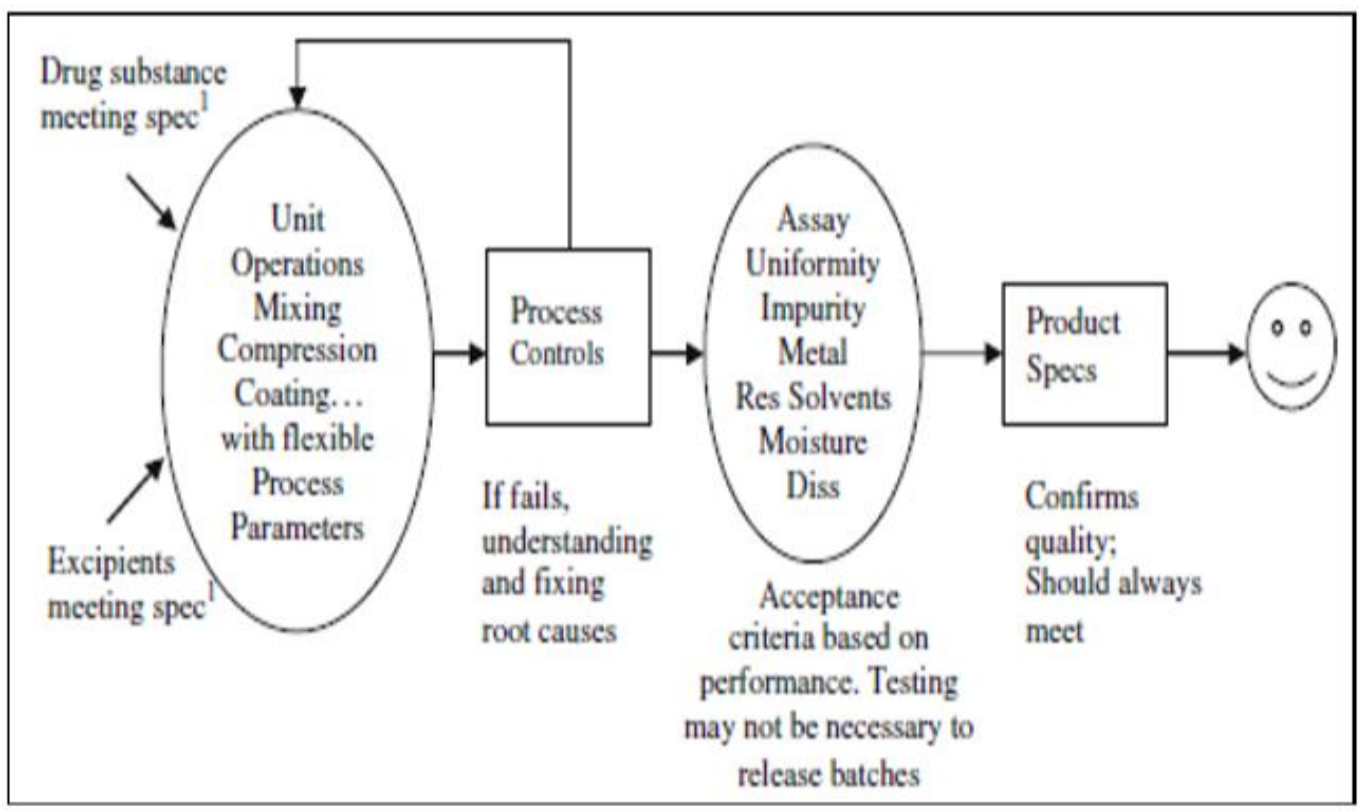

Table 1: A Simplified Quality Assurance Diagram under the QbD for Generic Drugs ${ }^{2}$

\section{Process Optimization:}

The development and commercial release of a globally marketed pharmaceutical drug product necessarily begins in the realm of the very small. Drug discovery may focus on the molecular level, and early formulation may deal with only gram quantities of material. It is at the early formulation stage, however, that a tentative sequence of physico chemical operations is initially

Proposed and developed to transform the raw materials into a drug product with the desired quality attributes (e.g., potency, dissolution, etc.) At this early stage, these experimental operations are carried out in bench top or small pilot-scale equipment, and the process knowledge in the form of raw data obtained from these experiments is specific to that scale. Process optimization is the practice by which process knowledge is developed and formulated in such a way that it can be applied effectively to guide equipment selection process parameters, process conditions, and process control strategies, irrespective of scale. ${ }^{3,4}$

An HPMC based extended release tablet formulation of a model anti-Hyperlipidemic drug is developed by dry granulation process. The manufacturing stages involve sifting, blending, blend lubrication, roller compaction, compression and coating.

The aim of our study was to define the design space of Blending operation, dry granulation and tablet compression process. In the first part, the assessment of process and formulation factors (critical material and process parameters) and their influence on critical quality attributes of intermediate and finished product was performed. Dry granulation parameters and compression force were varied, in order to develop new design space, evaluating their influence on tablets characteristics.

\section{MATERIALS AND METHODS:}

Materials: Materials used in the presented study for the granulation and tableting experiments were: Fluvastatin sodium (TEVA API India limited.), Glyceryl behenate (Compritol 888 ATO, Gattefosse), Pregelatinized Starch (Starch 1500 - Colorcon), Hypromellose (Methocel K100LV CR - Colorcon), Potassium Hydrogen Carbonate (Merck KgaA
Germany), Magnesium Stearate (Peter Graven) and Opadry Pink 81W42236 (Colorcon)

Manufacturing procedure: Matrix tablets were prepared by dry granulation method with the formula optimized composition as given in Table 1.

Table 1: Final Formula Composition

\begin{tabular}{|l|l|l|}
\hline S.N. & Ingredient & $\begin{array}{l}\text { Qunatity } \\
\text { (mg/tab) }\end{array}$ \\
\hline 1 & Fluvastatin sodium & 90.47 \\
\hline 2 & Glyceryl Behenate & 52.74 \\
\hline 3 & Pregelatinized Starch & 87.34 \\
\hline 4 & Hypromellose & 70.25 \\
\hline 5 & Potassium Hydrogen Carbonate & 14.20 \\
\hline 6 & Magnesium Stearate & 5.0 \\
\hline & Core Tablet Weight & 320 \\
\hline & Coating agent & \\
\hline 7 & Opadry Pink & 4 \\
\hline 8 & Purified Water & NA \\
\hline & Coated tablet weight & 324 \\
\hline
\end{tabular}

The manufacturing procedure for tablet production is as follows: Fluvastatin Sodium and other excipients except Magnesium Stearate were initially passed through 20\# sieve. The sifted material is blended for suitable time interval in a lab scale bin blender. The blended material is lubricated with Magnesium Stearate sifted through \#40 sieve for 5 minutes. The lubricated blend is compacted in Alexanderwerk WP200 roller compactor at suitable parameters to arrive at desired granular material. The obtained granules were lubricated with extra granular Magnesium Stearate for 5 minutes and resulting granules were evaluated for the flow properties. Tablets were compressed using $10.0 \mathrm{~mm}$ round shaped punches on KORSCH XM-12 compression machine. As per the process optimization plan different critical process parameters were evaluated and studied for their effect on critical quality attributes or quality target product profile (QTPP) of products. The details of equipment are used for various manufacturing process and their capacities areas listed in Table 2. 
Table 2: List of Equipment Utilized for Batch Manufacturing

\begin{tabular}{|l|l|l|l|}
\hline $\begin{array}{l}\text { Manufacturing } \\
\text { Process }\end{array}$ & Equipment used & Capacity & Manufacturer, Model No \\
\hline Dispensing & Dispensing Booth & Not Applicable & Marc-Aire, 3300DFB \\
\hline Sifting & Vibrosifter & Not Applicable & Jiangsu Gui Bao, ZS 350 \\
\hline Blending & Bin blender & $10 \mathrm{~L}, 30 \mathrm{~L}, 50 \mathrm{~L}$ and 100L & Zhejiang Canaan, HSD 100 \\
\hline Blend lubrication & Bin blender & $10 \mathrm{~L}, 30 \mathrm{~L}, 50 \mathrm{~L}$ and 100L & Zhejiang Canaan, HSD 100 \\
\hline Roller compaction & Alexanderwerk WP200 & $200 \mathrm{Kg} /$ hour & Alexanderwerk, WP200 \\
\hline Granules lubrication & Bin blender & $10 \mathrm{~L}, 30 \mathrm{~L}, 50 \mathrm{~L}$ and 100L & Zhejiang Canaan, HSD 100 \\
\hline Compression & $\begin{array}{l}\text { KORSCH XM 12 } \\
\text { Compression machine }\end{array}$ & $\begin{array}{l}\text { M station Single layer and bi-layer } \\
\text { Max speed: 60rpm }\end{array}$ & KORSCH XM 12 \\
\hline Coating & Glatt GMPC II & 9L, 56L & Glatt GMPC II \\
\hline
\end{tabular}

Based on scientific understanding and prior knowledge, a risk assessment of the potential impact of the unit operations on the drug product CQAs was completed. Table
3 shows the result of the risk assessment and identifies the unit operations which require further investigation to determine the appropriate control strategy.

Table 3: Risk Matrix for Drug Product CQAS for Each Unit Operation.

\begin{tabular}{|l|l|l|l|l|l|}
\hline \multicolumn{9}{|l|}{ Unit Operation } \\
\hline DP CQAs & Blending & $\begin{array}{l}\text { Blend } \\
\text { Lubrication }\end{array}$ & $\begin{array}{l}\text { Roller } \\
\text { compaction }\end{array}$ & $\begin{array}{l}\text { Granules } \\
\text { lubrication }\end{array}$ & Compression \\
\hline Appearance & Low & Low & Low & Low & High \\
\hline Identity & Low & Low & Low & Low & Low \\
\hline Assay & Low & Low & Low & Low & High \\
\hline $\begin{array}{l}\text { Content } \\
\text { uniformity }\end{array}$ & High & High & High & High & High \\
\hline $\begin{array}{l}\text { Dissolution } \\
\text { Low }\end{array}$ & & Low & High & Low & High \\
\hline
\end{tabular}

\section{Process Optimization - Blending and Blend Lubrication Unit Operation:}

The manufacturing process uses a blending step followed by roller compaction to obtain granules for compression. The blend includes approximately $26 \%$ active and $74 \%$ excipients, which is mostly Glyceryl behenate and Pregelatinized Starch. Despite the presence of roller compaction and granules blending step (lubrication) later in the process train, this processing step was deemed critical because development studies indicated that material insufficiently blended or lubricated at this stage ultimately leads to unacceptable content uniformity of the finished drug product and roller sticking tendency during compaction respectively. Blending process was done for 12 minutes at $12 \mathrm{rpm}$ with intermittent sampling was done at 4 minutes, 8 minutes and 12 minutes. The 12 minutes blended material is lubricated for 5 minutes at $12 \mathrm{rpm}$ with intermittent sampling at 3 minutes and 5 minutes. Details are as listed in Table 4.

Table 4: Process Parameters for Blending and Blend Lubrication Batch Size - 20, 000 Tablets, 6.480 Kg

\begin{tabular}{|l|l|l|l|l|l|}
\hline & \multicolumn{2}{|l|}{ Blending } & \multicolumn{2}{l|}{ Blend Lubrication } \\
\hline Batch No & Trial 1 & Trial 2 & Trial 3 & Trial 1 & Trial 2 \\
\hline Machine RPM & RPM 12 & RPM 12 & RPM 12 & RPM 12 & RPM 12 \\
\hline $\begin{array}{l}\text { Blending time } \\
\text { (minutes) }\end{array}$ & 4 minutes & 8 minutes & 12 minutes & 3 minutes & 5 minutes \\
\hline Total Revolution & 48 revolutions & 96 revolutions & 144 revolutions & 36 revolutions & 60 revolutions \\
\hline
\end{tabular}

The sampled materials are analyzed for individual blend content uniformity as per the approved method and evaluated for blend content uniformity at various blending time intervals. 
Process Optimization - Roller compaction unit operation: 5,6

The purpose of the roller compaction and milling stages is to produce granulated product that is suitable for subsequent blending and compression. The initial blend is transferred to the roller compactor where a screw-feeder drives it between two rollers, which compact the material. The compacted ribbon is then broken up and passes through a rotating impellor screen mill. Critical process parameter for roller compaction process is Roller force, roller gap, roller speed and mill screen size. The parameters under evaluation are Roller force, roller gap and roller speed. A design experiment of 2 Level Factorial design with 1 center point is applied to evaluate the roller compaction parameters on critical quality attributes of drug product. The compacted granules are lubricated and compressed into tablets at predetermined parameters. The factors and range for roller compaction parameter studied is as in Table 5.

Table 5: Factor Studied (Critical Process Parameters)

\begin{tabular}{|l|l|l|l|l|}
\hline Factor & Name & Units & Minimum & Maximum \\
\hline Factor 1 & Roller Force & Bar & 30 & 50 \\
\hline Factor 2 & Roller Speed & Mm & 3 & 9 \\
\hline Factor 3 & Roller Gap & Rpm & 2 & 4 \\
\hline
\end{tabular}

Table 6: DOE Run Details, Batch Size 20, 000 Tablets, $6.480 \mathrm{Kg}$

\begin{tabular}{|l|l|l|l|l|l|l|l|l|l|l|}
\hline \multicolumn{10}{|c|}{ Trial 1 Lubricated Blend } \\
\hline Run & Units & $\mathbf{1}$ & $\mathbf{2}$ & $\mathbf{3}$ & $\mathbf{4}$ & $\mathbf{5}$ & $\mathbf{6}$ & $\mathbf{7}$ & $\mathbf{8}$ & $\mathbf{9}$ \\
\hline A: Force & KN/cm & 30 & 50 & 30 & 50 & 40 & 50 & 30 & 50 & 30 \\
\hline B: Gap & $\mathrm{mm}$ & 4 & 4 & 2 & 4 & 3 & 2 & 2 & 2 & 4 \\
\hline Speed & rpm & 3 & 3 & 3 & 9 & 6 & 9 & 9 & 3 & 9 \\
\hline
\end{tabular}

For tracking and understanding the granules are coded as Trial 1-A to Trail 1-I. The impact of these parameters on Critical Quality Attributes of Drug Products and Intermediates like Bulk density, Tapped density, PSD \#60 meshes Cum. \% retained and tablet dissolution profile is studied.

\section{Process Optimization - Granulation Lubrication Unit Operation:}

Following the roller compaction and milling, the milled granulation is blended with extragranular excipients in a third blending operation. The granules are mixed with $1.0 \%$ magnesium stearate (as lubricant). Based on the development data, the blending parameter targets listed in Table 7 are acceptable for the proposed commercial scale lubrication blending process. Because studies have shown that wide variations in both blending time and blender fill volume have negligible impact on any CQA, this unit operation is considered robust and has no critical process parameters.

Table 7: Process Parameters for Granules Lubrication Batch Size - 20, 000 Tablets, 6.480 Kg

\begin{tabular}{|l|l|}
\hline \multicolumn{2}{|c|}{ Granules Lubrication } \\
\hline Batch No & Trial 1 \\
\hline Machine RPM & 12 RPM \\
\hline Blending time (minutes) & 5 minutes \\
\hline Total Revolution & 60 revolutions \\
\hline
\end{tabular}

The sampled materials are analyzed for individual blend content uniformity as per the approved method and evaluated for blend content uniformity at various blending time intervals. No further optimization is being done for this unit operation.

\section{Compression process parameters:}

7, 8 During compression of the tablet, Compression Force (Pre-Compression and Main Compression) and machine speed should be optimized. Compression parameters for compression force and speed stud study are shown in Table 8 and 9 respectively. Tablets of these batches were evaluated for Thickness, Weight variation, Friability and dissolution study. 
Table 8: Compression Force Study Batch Size - 20, 000 Tablets, $6.480 \mathrm{Kg}$

\begin{tabular}{|l|l|l|l|l|}
\hline \multicolumn{1}{|c|}{ Parameter } & \multicolumn{3}{|c|}{ Optimization batch } \\
\hline & $\begin{array}{l}\text { High compression } \\
\text { force }\end{array}$ & $\begin{array}{l}\text { Target } \\
\text { compression force } \\
\text { force }\end{array}$ & $\begin{array}{l}\text { Low compression } \\
\text { Without } \\
\text { precompression } \\
\text { force }\end{array}$ \\
\hline $\begin{array}{l}\text { Pre-compression } \\
\text { force (Kn) }\end{array}$ & 8.4 & 3.3 & 1.3 & 0.2 \\
\hline $\begin{array}{l}\text { Main compression } \\
\text { force (Kn) }\end{array}$ & 35.7 & 24.2 & 16.4 & 12 \\
\hline Dosing (mm) & 5.3 & & 4.9 & 4.9 \\
\hline Machine RPM & 15 & 5.0 & 12 & 12 \\
\hline
\end{tabular}

Table 9: Compression Machine Speed Study

\begin{tabular}{|l|l|l|l|}
\hline Parameter & \multicolumn{3}{|c|}{ Optimization batch } \\
\hline & High speed - 40 RPM & Target speed - 20 RPM & Low speed - 10 RPM \\
\hline Main compression force (Kn) & 24 & 24 & 24 \\
\hline Dosing (mm) & 5 & 5 & 5 \\
\hline Machine RPM & 40 & 20 & 10 \\
\hline
\end{tabular}

\section{RESULTS AND DISCUSSION:}

Process Optimization - Blending and Blend Lubrication Unit Operation: For batch No coded as Trail 1, blend uniformity data at blending stage and blend lubrication stage is tabulated in Table 9 and graphical representation of \% RSD with mixing time is shown in Figure 2 and 3. From the results we can say that \% RSD is less than $4.0 \%$ at all time intervals. At blending stage with increase in blending time from 4 minutes to 12 minutes the \% RSD is minimum and content uniformity is improved. Also with blend lubrication the $\%$ RSD reduced to less than $2.0 \%$ at 5 minutes blend lubrication time. So finally 12 minutes of blending time and five minutes of blend lubrication time was finalized.

Table 10: Blend Uniformity Data at Blending and Blend Lubrication Stage.

\begin{tabular}{|c|c|c|c|c|c|}
\hline \multicolumn{6}{|c|}{ Fluvastatin ER Tablets 80 mg - Trail 1} \\
\hline \multirow[t]{2}{*}{ Sample } & \multicolumn{3}{|c|}{ Blending stage } & \multicolumn{2}{|c|}{ Blend Lubrication } \\
\hline & 4 minutes & 8 minutes & 12 minutes & 3 minutes & 5 minutes \\
\hline & \multicolumn{5}{|c|}{$\%$ drug content (Fluvastatin) } \\
\hline A & 95.8 & 94.4 & 100.9 & 97 & 98.2 \\
\hline B & 98.9 & 101.2 & 99.3 & 103.5 & 99.8 \\
\hline $\mathrm{C}$ & 105.5 & 99.7 & 100.7 & 103.0 & 98.8 \\
\hline $\mathrm{D}$ & 96.9 & 98.3 & 101.5 & 99.0 & 100.8 \\
\hline $\mathrm{E}$ & 96.6 & 98.8 & 100.0 & 97.2 & 101.3 \\
\hline $\mathrm{F}$ & 96.8 & 101.8 & 100.2 & 102.2 & 98.7 \\
\hline G & 101.7 & 100.3 & 100.9 & 95.6 & 100.3 \\
\hline $\mathrm{H}$ & 98.0 & 100.7 & 103.0 & 98.7 & 101.0 \\
\hline I & 97.6 & 101.8 & 104.0 & 101.3 & 102.2 \\
\hline $\mathrm{J}$ & 99.4 & 98.6 & 100.4 & 99.2 & 98.5 \\
\hline Minimum & 95.8 & 94.2 & 99.3 & 95.6 & 97.1 \\
\hline Maximum & 105.5 & 101.8 & 104.0 & 103.5 & 102.2 \\
\hline Mean & 98.8 & 99.5 & 101.1 & 99.57 & 99.9 \\
\hline \%RSD & 2.99 & 2.28 & 1.39 & 2.85 & 1.57 \\
\hline
\end{tabular}




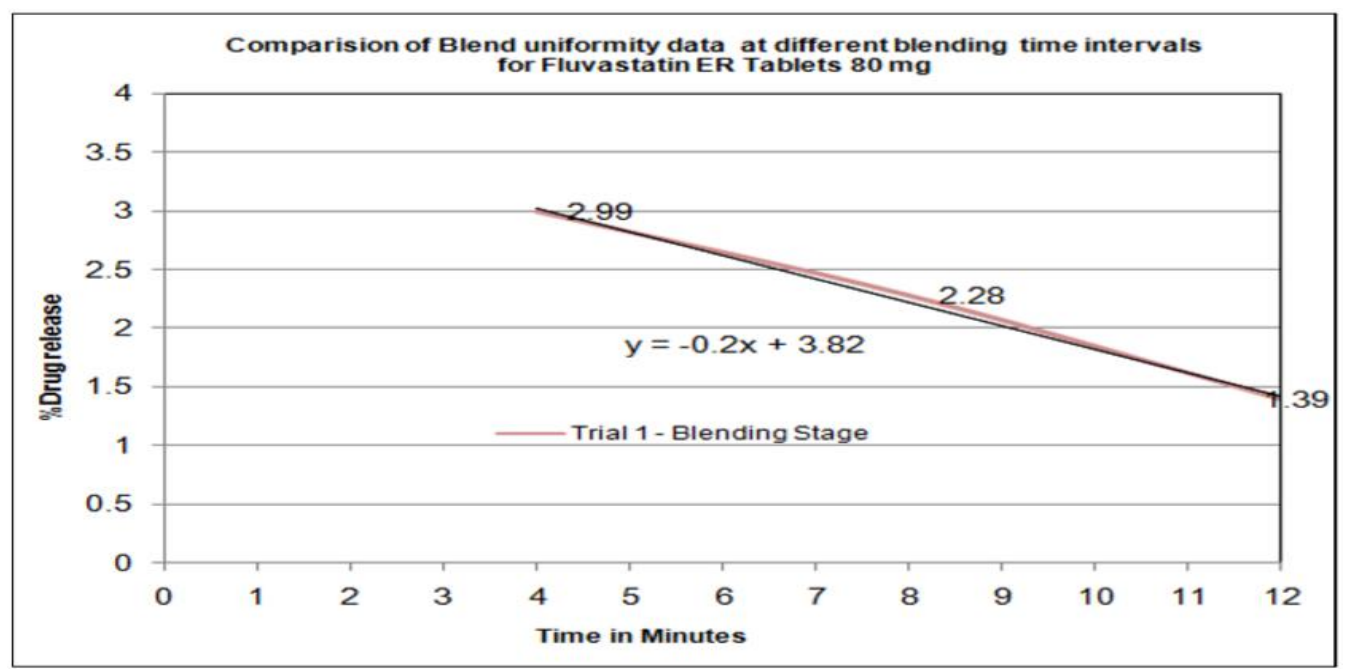

Figure 2: Comparison of Blend Uniformity Data at Different Blending Time Intervals for Fluvastatin ER Tablets 80 Mg

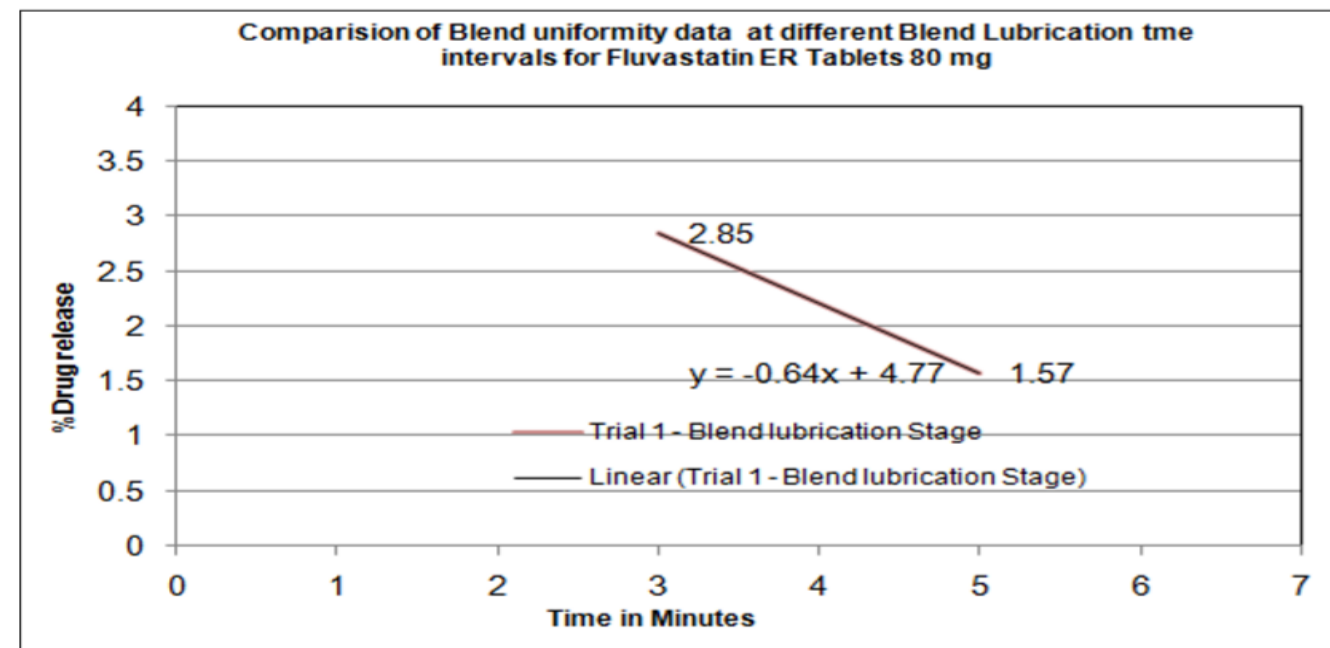

Figure 3: Comparison of Blend Uniformity Data at Different Blend Lubrication Time Intervals for Fluvastatin ER Tablets $80 \mathrm{mg}$

Process Optimization - Roller compaction unit operation: The trial batch In-process data for granules parameter and Dissolution profile for tablets at various time points is collated in tabular form. The analysed results, statistical data, Tablet parameters and dissolution profile are tabulated in Table 10 - 13. The statistical summary for the Design of experiments factorial model is tabulated in Table10. The contour plot, Pareto chart and Overlay plot for effect of model on evaluated parameters is as in Fig. 4 and 5.

Table 11: DOE Run Details and Observations

\begin{tabular}{|c|c|c|c|c|c|c|c|c|c|c|}
\hline $\begin{array}{l}0 \\
z \\
\text { in }\end{array}$ & $\underset{\Xi}{\Xi}$ & 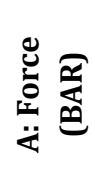 & 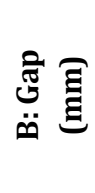 & 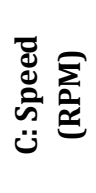 & 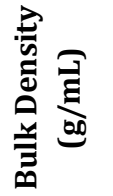 & 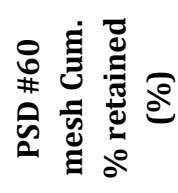 & 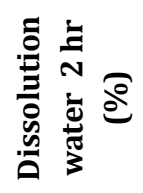 & 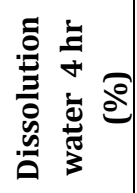 & 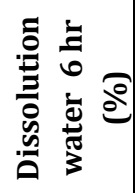 & 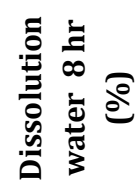 \\
\hline 3 & 1 & 30 & 4 & 3 & 0.491 & 39.68 & 18 & 45 & 71 & 94 \\
\hline 4 & 2 & 50 & 4 & 3 & 0.554 & 68.74 & 20 & 46 & 73 & 95 \\
\hline 1 & 3 & 30 & 2 & 3 & 0.509 & 53.76 & 18 & 43 & 69 & 96 \\
\hline 8 & 4 & 50 & 4 & 9 & 0.551 & 64.94 & 19 & 45 & 72 & 92 \\
\hline 9 & 5 & 40 & 3 & 6 & 0.544 & 62.16 & 18 & 45 & 72 & 93 \\
\hline 6 & 6 & 50 & 2 & 9 & 0.583 & 66.63 & 21 & 46 & 74 & 94 \\
\hline 5 & 7 & 30 & 2 & 9 & 0.5 & 54.94 & 17 & 37 & 64 & 92 \\
\hline 2 & 8 & 50 & 2 & 3 & 0.552 & 72.2 & 21 & 46 & 74 & 96 \\
\hline 7 & 9 & 30 & 4 & 9 & 0.488 & 44.59 & 16 & 39 & 68 & 97 \\
\hline
\end{tabular}


Table 12: DOE Summary: Statistical Analysis.

\begin{tabular}{|l|c|c|c|c|c|c|c|c|c|c|c|c|}
\hline $\begin{array}{l}\text { ANOVA } \\
\text { Analysis }\end{array}$ & \multicolumn{2}{|l|}{ Bulk density } & \multicolumn{2}{l|}{$\begin{array}{l}\text { PSD \#60 mesh } \\
\text { Retained }\end{array}$} & \multicolumn{2}{l|}{$\begin{array}{l}\text { Dissolution 2 } \\
\text { hour }\end{array}$} & \multicolumn{2}{l|}{$\begin{array}{l}\text { Dissolution 4 } \\
\text { hour }\end{array}$} & \multicolumn{2}{l}{$\begin{array}{l}\text { Dissolution 6 } \\
\text { hour }\end{array}$} & \multicolumn{2}{l}{$\begin{array}{l}\text { Dissolution 8 } \\
\text { hour }\end{array}$} \\
\hline & $*$ & $\#$ & $*$ & $\#$ & $*$ & $\#$ & $*$ & $\#$ & $*$ & $\#$ & $*$ & $\#$ \\
\hline Model & 0.006 & Yes & 0.006 & Yes & 0.008 & Yes & $\mathbf{0 . 0 8 1}$ & NA & $\mathbf{0 . 0 5 9}$ & NA & $\mathbf{0 . 3 3 9}$ & NA \\
\hline Roller Force & 0.001 & Yes & 0.001 & Yes & 0.002 & Yes & 0.0035 & Yes & 0.0019 & Yes & 0.024 & No \\
\hline Roller Gap & 0.13 & No & 0.061 & No & 0.082 & No & 0.645 & No & 0.745 & No & 0.390 & No \\
\hline Roller Speed & 0.601 & No & 0.082 & No & 0.089 & No & 0.992 & No & 0.156 & No & 0.249 & No \\
\hline
\end{tabular}

Note: * is p- values, \# is Signal. Response effect.

Table 11 shows the tablet physical testing results of tablets prepared using different granules using roller compaction granulation parameter. Data show goods similarity between different roller compaction parameter. The results also show that the speed at which the roller compactor equipment was operated at did not influence tablet crushing strength values.

Table 13: Tablet Physical Parameters for Tablets Compressed Using Granules Compacted at Different Parameters.

\begin{tabular}{|c|c|c|c|c|c|c|c|c|c|}
\hline Parameter & $\begin{array}{c}\text { Trial 1- } \\
\text { A }\end{array}$ & $\begin{array}{l}\text { Trial 1- } \\
\text { B }\end{array}$ & $\begin{array}{c}\text { Trial 1- } \\
\text { C }\end{array}$ & $\begin{array}{l}\text { Trial 1- } \\
\text { D }\end{array}$ & $\begin{array}{c}\text { Trial 1- } \\
\text { E }\end{array}$ & $\begin{array}{c}\text { Trial 1- } \\
\text { F }\end{array}$ & $\begin{array}{l}\text { Trial 1- } \\
\text { G }\end{array}$ & $\begin{array}{c}\text { Trial 1- } \\
\mathbf{H}\end{array}$ & $\underset{\text { I }}{\text { Trial 1- }}$ \\
\hline $\begin{array}{l}\text { Individual } \\
\text { weight(mg) }\end{array}$ & $\begin{array}{c}299- \\
306\end{array}$ & $\begin{array}{l}306- \\
313\end{array}$ & $\begin{array}{c}299- \\
308\end{array}$ & $\begin{array}{c}300- \\
305\end{array}$ & $\begin{array}{c}295- \\
306\end{array}$ & $\begin{array}{c}291- \\
306\end{array}$ & $\begin{array}{c}298- \\
305\end{array}$ & $\begin{array}{c}298- \\
308\end{array}$ & $\begin{array}{c}299- \\
304\end{array}$ \\
\hline Thickness(mm) & $\begin{array}{c}4.11- \\
4.20\end{array}$ & $\begin{array}{c}4.14- \\
4.25\end{array}$ & $\begin{array}{c}4.10- \\
4.20\end{array}$ & $\begin{array}{c}4.08- \\
4.12\end{array}$ & $\begin{array}{c}4.14- \\
4.22\end{array}$ & $\begin{array}{l}4.14- \\
4.24\end{array}$ & $\begin{array}{l}4.15- \\
4.24\end{array}$ & $\begin{array}{c}4.18- \\
4.26\end{array}$ & $\begin{array}{l}4.18- \\
4.24\end{array}$ \\
\hline Hardness(N) & $52-61$ & $52-68$ & $60-65$ & $52-65$ & $55-64$ & $39-50$ & $52-64$ & $50-64$ & $51-62$ \\
\hline Friability (1\%) & Nil & Nil & Nil & Nil & Nil & Nil & Nil & Nil & Nil \\
\hline Flow Properties & Good & Good & Good & Good & Good & Good & Good & Good & Good \\
\hline
\end{tabular}

Table 14: Tablet Dissolution Profile for Tablets Compressed Using Granules Compacted at Different Parameters

\begin{tabular}{|l|l|l|l|l|l|l|l|l|l|}
\hline $\begin{array}{l}\text { Dissolution Profile in } \\
\text { Water at 50 rpm } \\
\text { (Time point in Hours) }\end{array}$ & \multicolumn{6}{l|}{$\begin{array}{l}\text { Tablet dissolution Profile for tablets compressed using granules compacted at } \\
\text { different parameters }\end{array}$} \\
\hline & $\begin{array}{l}\text { Trial } \\
\text { 1-A }\end{array}$ & $\begin{array}{l}\text { Trial } \\
\text { 1-B }\end{array}$ & $\begin{array}{l}\text { Trial } \\
\text { 1-C }\end{array}$ & $\begin{array}{l}\text { Trial } \\
\text { 1-D }\end{array}$ & $\begin{array}{l}\text { Trial } \\
\text { 1-E }\end{array}$ & $\begin{array}{l}\text { Trial } \\
\text { 1-F }\end{array}$ & $\begin{array}{l}\text { Trial } \\
\text { 1-G }\end{array}$ & $\begin{array}{l}\text { Trial } \\
\text { 1-H }\end{array}$ & Trial 1-I \\
\hline 2 Hours & 18 & 20 & 18 & 19 & 18 & 21 & 17 & 21 & 16 \\
\hline 4 Hours & 45 & 46 & 43 & 45 & 45 & 46 & 37 & 46 & 39 \\
\hline 6 Hours & 71 & 73 & 69 & 72 & 72 & 74 & 64 & 74 & 67 \\
\hline 8 Hours & 95 & 96 & 92 & 93 & 92 & 94 & 91 & 97 & 95 \\
\hline
\end{tabular}

Note: Time point in Hours Condition - Water, 1000 ml, USPI-I(Basket ), Sampling at 2 Hours, 4 hours, 6 hours and 8 hours.

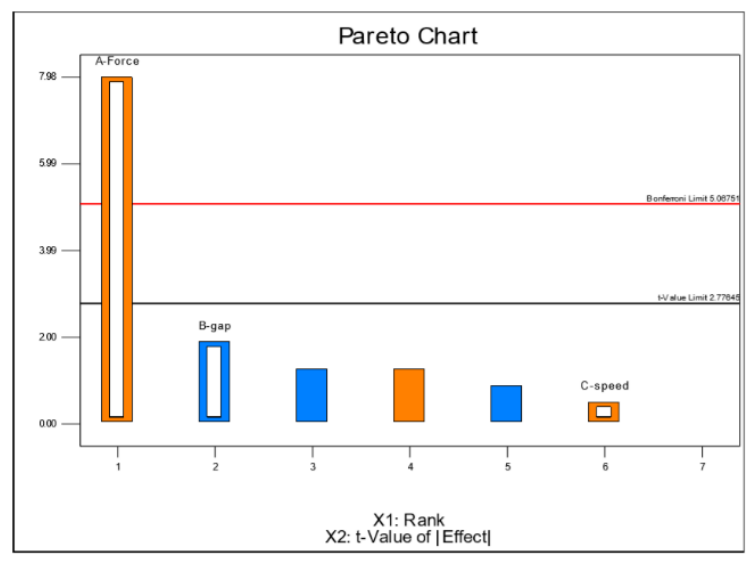

Pareto Chart for effect on Bulk density

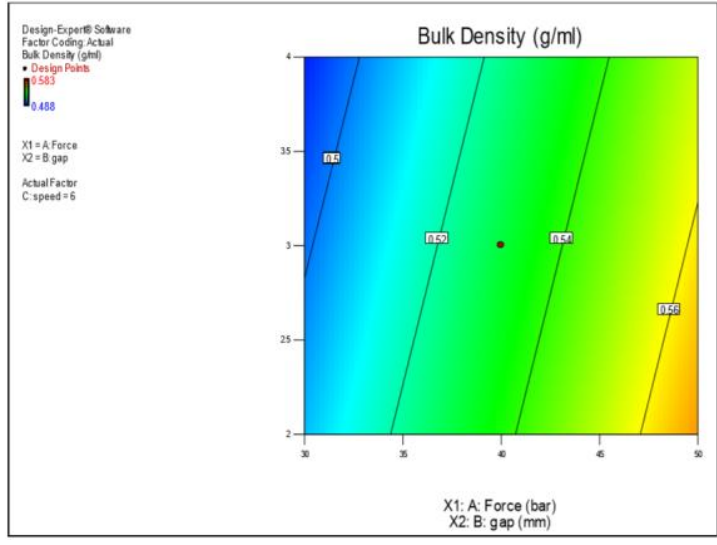

Contour plot for roll pressure and roller gap versus bulk density of granules. 


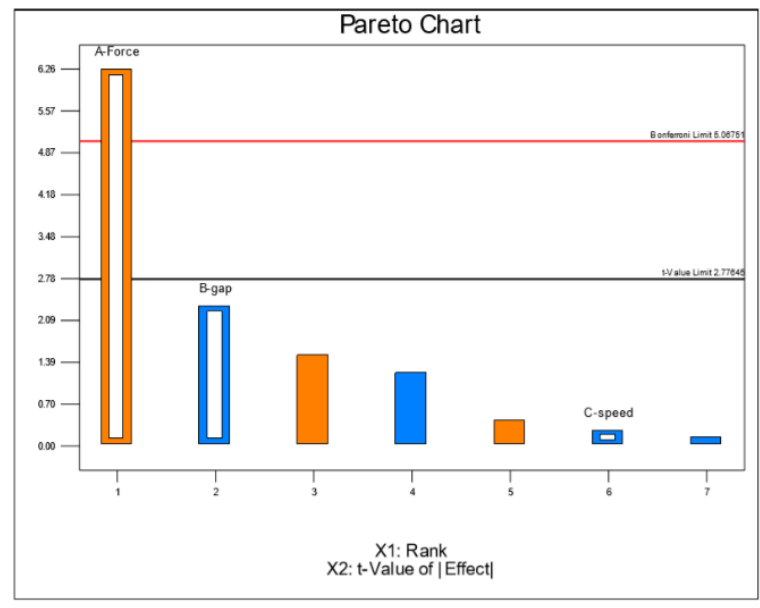

Pareto Chart for effect on PSD \#60 Mesh Cum. \%

Retained of granules 12493

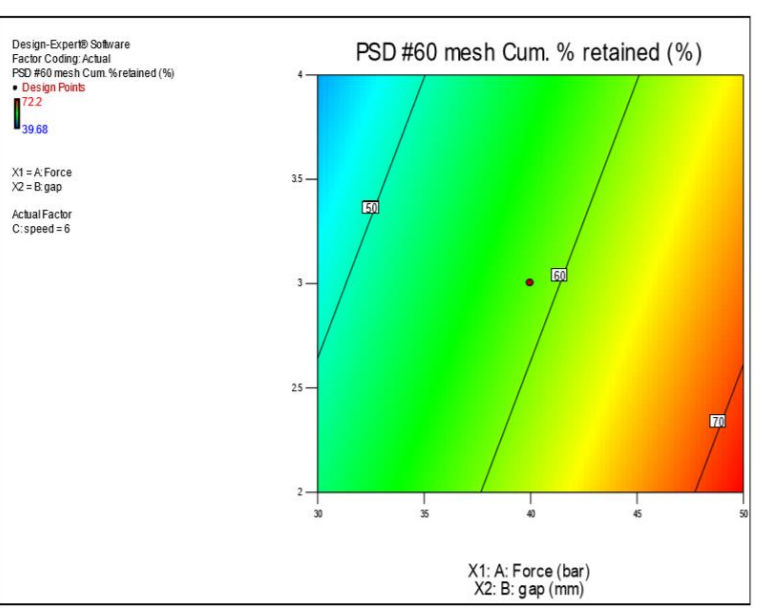

Contour plot for roll pressure and roller gap versus PSD \#60 Mesh Cum. \% Retained of granules.

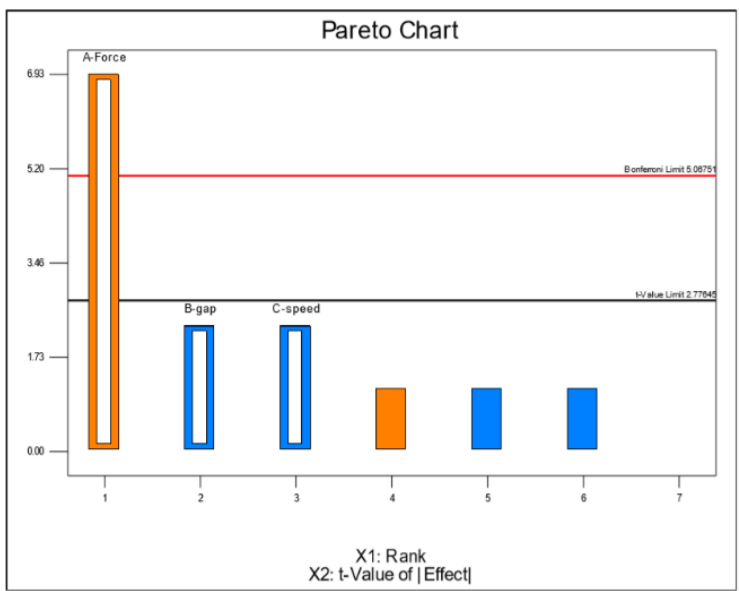

Pareto Chart for effect on Dissolution in water at 2 Hour

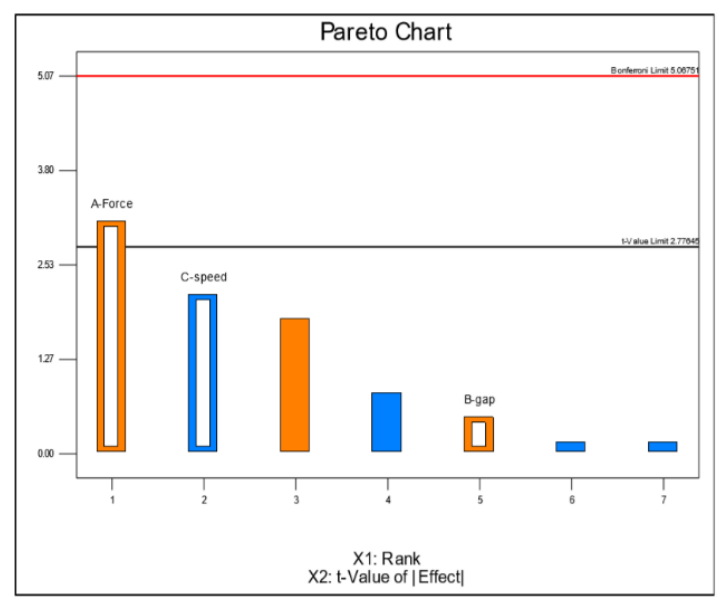

Pareto Chart for effect on Dissolution in water at 4 Hour

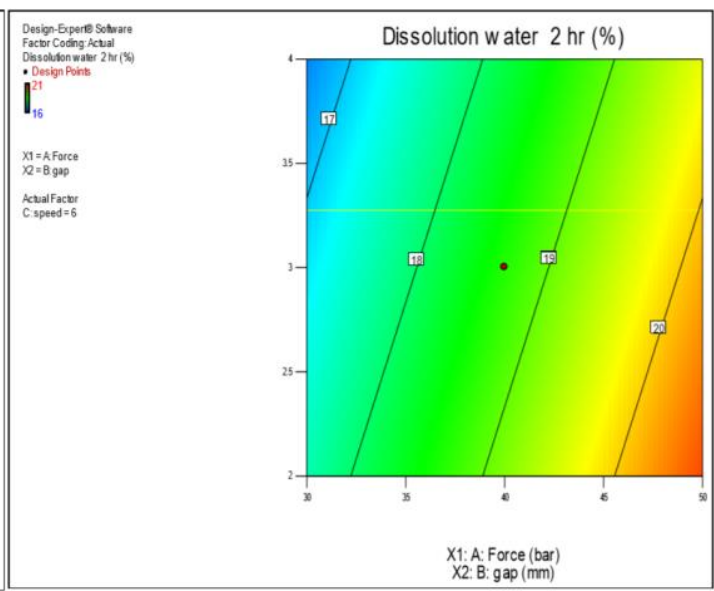

Contour plot for roll pressure and roller gap versus Dissolution in dissolution at 2 Hour

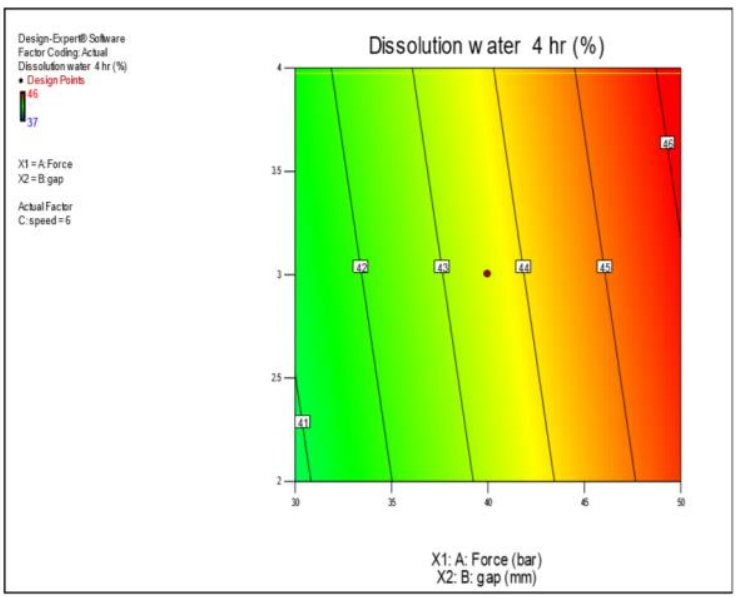

Contour plot for roll pressure and roller gap versus Dissolution in dissolution at 4 Hour. 


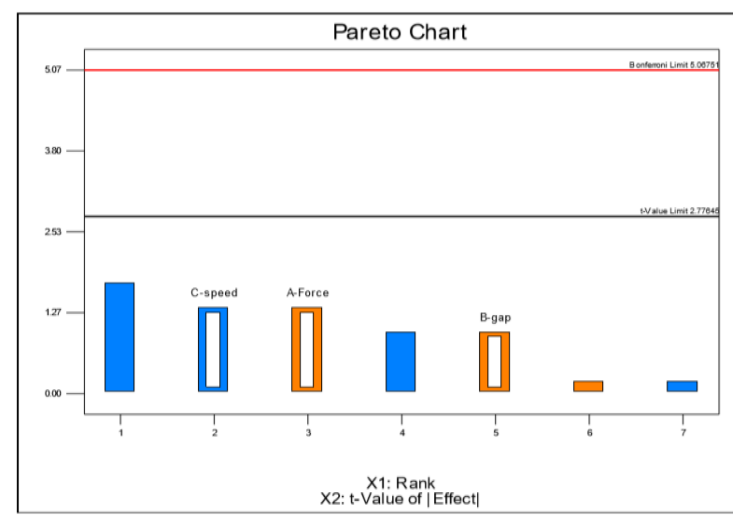

Pareto Chart for effect on Dissolution in water at 6 Hour

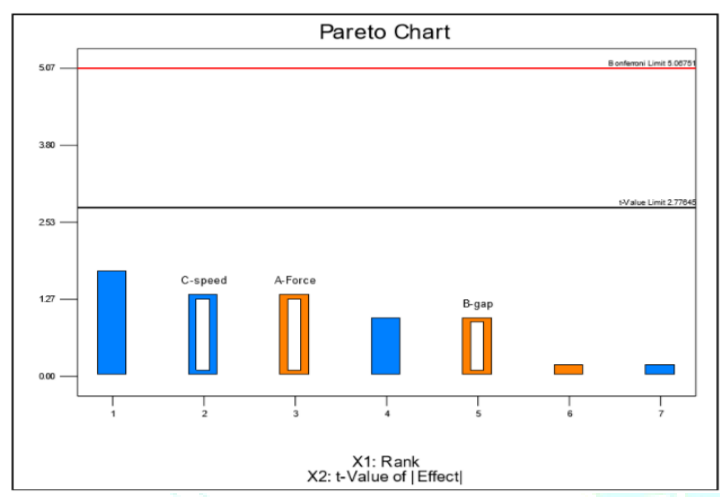

Pareto Chart for effect on Dissolution in water at 8 Hour.

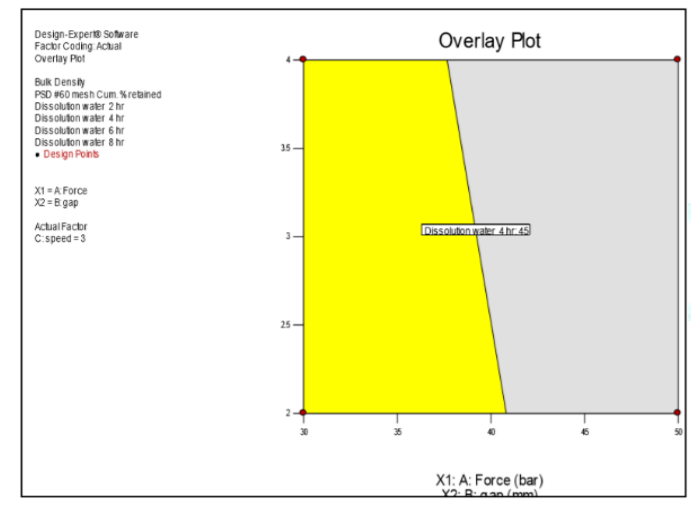

Multiple Responses Overlay Plot at Roller Sped $=3 \mathbf{r p m}$

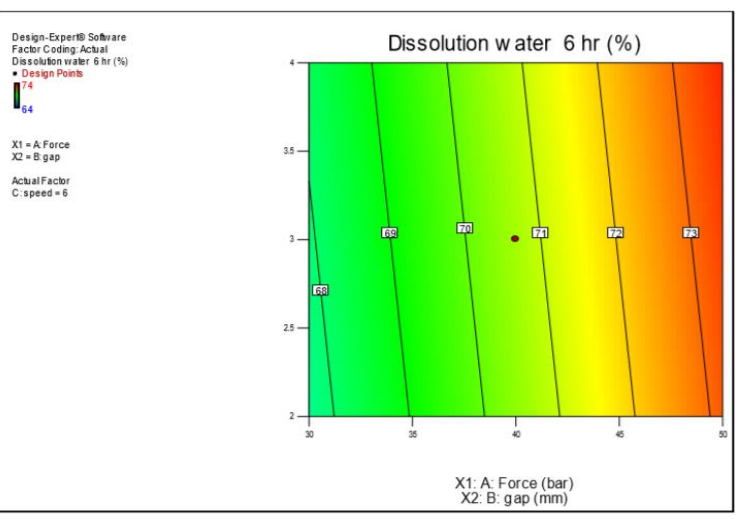

Contour plot for roll pressure and roller gap versus Dissolution in dissolution at 6 Hour

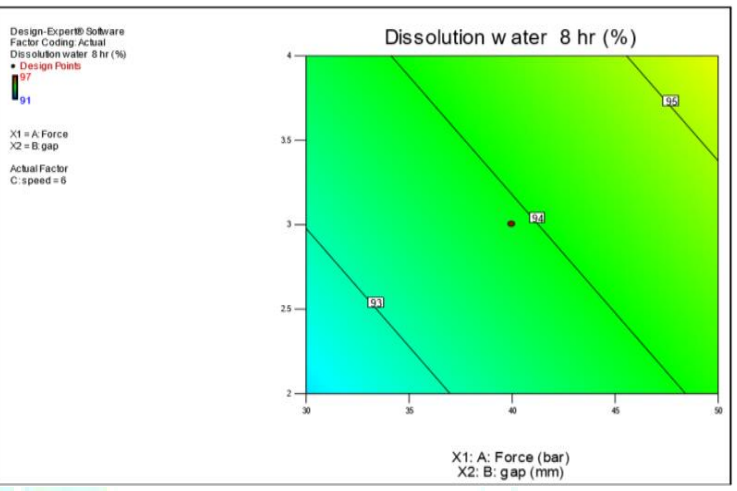

Contour plot for roll pressure and roller gap versus Dissolution in dissolution at 8 Hour.

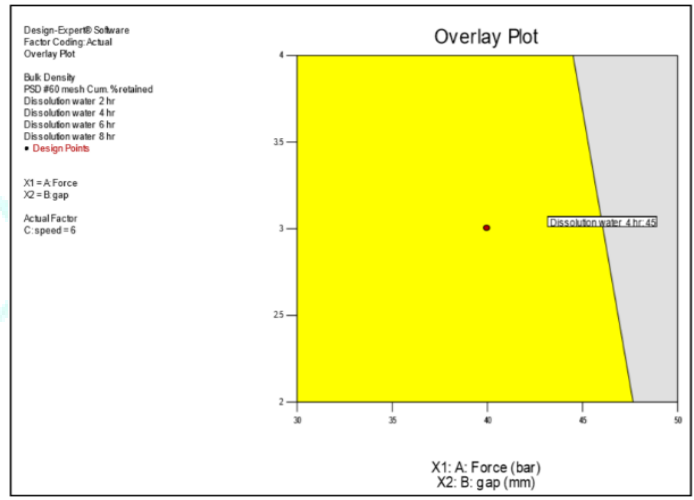

Multiple Responses Overlay Plot at Roller Sped $=6$ rpm

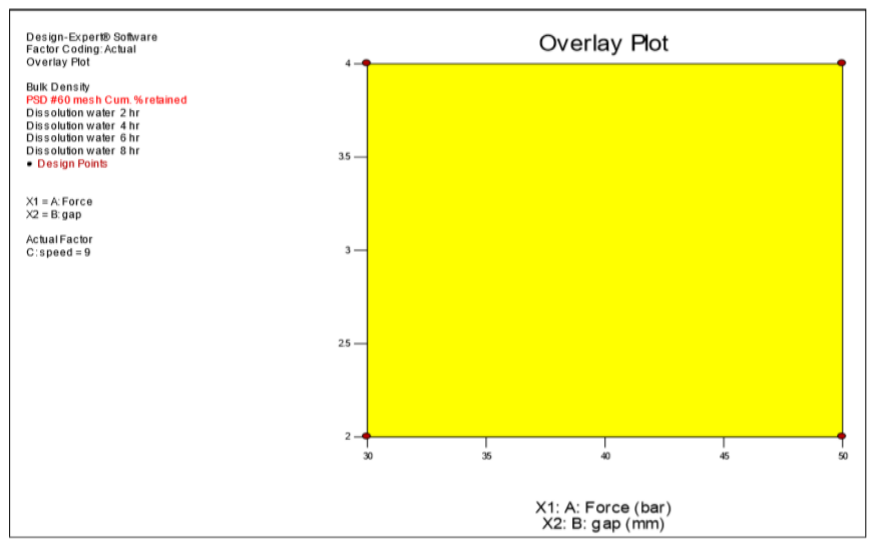

Multiple Responses Overlay Plot at Roller Sped = 9 rpm

Figure 5: The Multiple Responses Overlay Plot at Different Roller Speed (3 RPM, 6 RPM AND 9 RPM) 


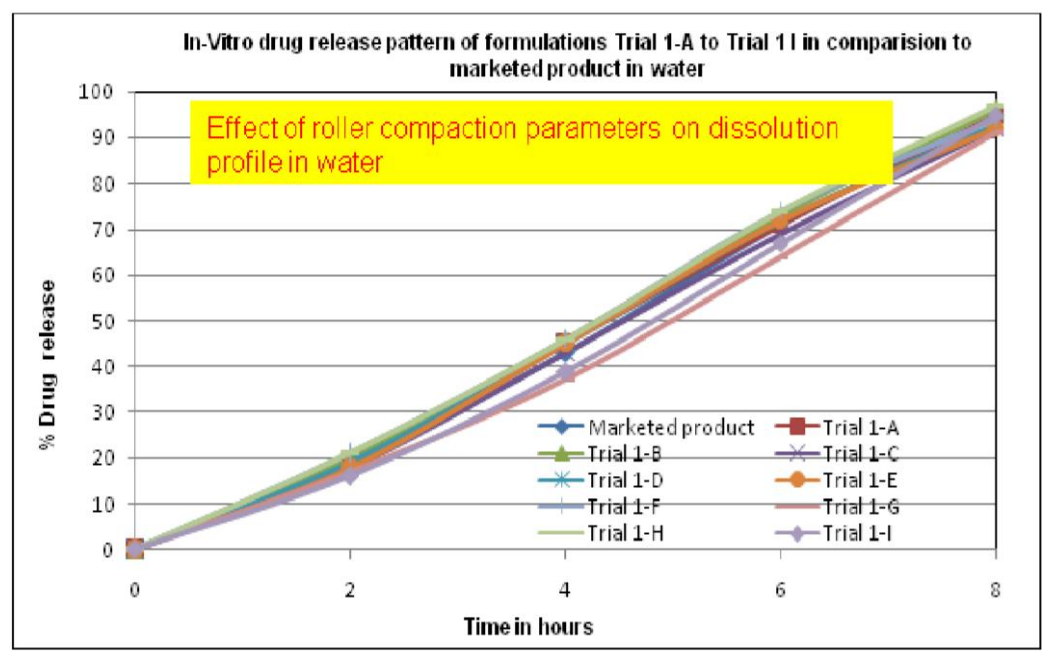

Figure 6: In-Vitro Drug Release Pattern of Formulations Trial 1-A to Trial 1-I In Comparison To Marketed Product in Water

For all the 9 different granules the granules bulk density and particle size distribution was evaluated and found to be satisfactory. There was no flow problem during compression nor tablet sticking tendency during compression. Roller pressure is the significant factor affecting all product attributes tested, but the operating range tested is within the design space (30 - 50 Bar). Roller gap may effect on the product attributes but not significant. Therefore the design space is what the operating range tested $(2-4 \mathrm{~mm})$. Roller speed was determined not to be critical process parameters. Therefore the design space is what the operating range tested (3-9 rpm). However the design space (overlay plot) indicates that at roller RPM of 9, the process gives a satisfactory properties for the granules. At 3 and $6 \mathrm{rpm}$ the Dissolution at 4 hours is on the higher side out of the specification limit. Further studies to be continued to optimize the process or to identify the acceptable dissolution release profile.

\subsection{Process Optimization - Compression unit operation:}

Post compression parameters such as thickness, hardness, friability, weight variation are given in following Table 14. As shown in Fig.7, there was no effect on dissolution profile of tablet produced at different compression force. There was no capping or sticking defects for the compressed tablets at different compression force. Therefore the evaluated maincompression range of $36-13 \mathrm{Kn}$ is suitable to achieve tablets of desired quality attributes. Also with minimal precompression force of $0.2 \mathrm{Kn}$ the binding of tablets were still reasonably good, as depicted in tablet parameters

Table 14: Tablet Physical Parameters for Tablets Compressed at Different Compression Parameter.

\begin{tabular}{|l|l|l|l|l|}
\hline Parameter & \multicolumn{4}{|c|}{ Compression force study } \\
\hline & $\begin{array}{l}\text { High compression } \\
\text { force }\end{array}$ & $\begin{array}{l}\text { Target } \\
\text { compression force }\end{array}$ & $\begin{array}{l}\text { Low compression } \\
\text { force }\end{array}$ & $\begin{array}{l}\text { Without } \\
\text { precompression force }\end{array}$ \\
\hline Individual weight(mg) & $296-306$ & $297-300$ & $295-302$ & $305-308$ \\
\hline Thickness(mm) & $4.06-4.15$ & $4.07-4.13$ & $4.10-4.14$ & $4.27-4.36$ \\
\hline Hardness(N) & $55-65$ & $54-64$ & $54-60$ & $43-56$ \\
\hline Friability (1\%) & Nil & Nil & Nil & Nil \\
\hline Flow Properties & Good & Good & Good & Good \\
\hline
\end{tabular}

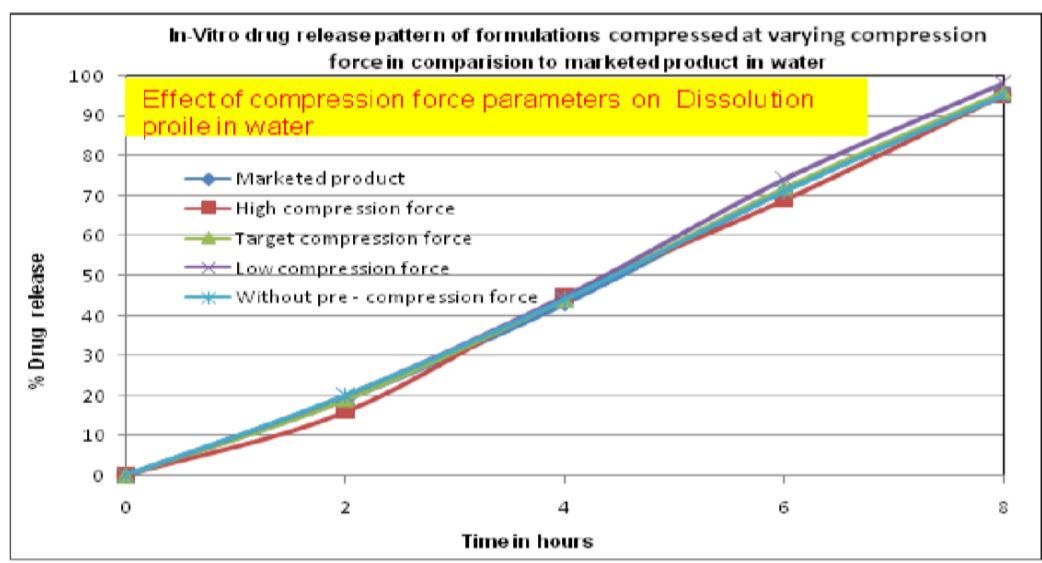

Figure 7: In-Vitro Drug Release Pattern of Formulations Compressed at Varying Compression Force in Comparison to Marketed Product In Water. 


\section{CONCLUSION:}

Tablet manufacturing by Dry granulation using roller compaction process is a widely used manufacturing process for poorly soluble drug having low bulk density. In manufacturing process, there are many factors which may affect final product. In this study all these critical process parameters were identified and optimized. Blending time and lubrication time in blender was also optimized. During roller compaction process the critical parameters were optimized using 3 factorial design with zero blocks. Roller compaction force is identified as the critical parameter affecting granules properties. During compression process, there was Tablet hardness which may affect release profile of drug. These parameters were also optimized. Finally its of the opinion that all the process parameters for formulation of Fluvastatin ER Tablets $80 \mathrm{mg}$ by using Dry Granulation process were optimized to make the process a robust and reproducible in scale up manufacturing.

\section{REFERENCES:}

1. EMA, 2014. Human Regulatory, Quality by Design, Guidance Documents. Accessed on 2016.06.13
2. Pallagi E, Ambrus R, Szabó-Révész P, Csóka I. Adaptation of the quality by design concept in early pharmaceutical development of an intranasal Nanosized formulation. International Journal of Pharmaceutics. 2015; 491:384 - 392.

3. Reddy BV, Navaneetha K, Reddy KVR. International Journal of Pharmacy and Pharmaceutical Sciences.2014; 6(4):312 - 317.

4. Kaur G, Sridhar DB, Gera M. Optimization of Roll Compaction/Dry Granulation Process for Poorly Flowable Antiviral Formulation. Am. J. PharmTech Res. 2012; 2(4):544 - 557.

5. Khorasani M et al., Process optimization of dry granulation based tableting line: Extracting physical material characteristics from granules, ribbons and tablets using near-IR (NIR) spectroscopic measurement

6. Hwang R, Noack RM. Application of design of experiments to pharmaceutical formulation development; 2(1):58 - 65.

7. Sutton S. Optimizing Tableting Processes with Quality by Design. Pharmaceutical Technology. 2012; 36(5).

8. Belic A, Skrjanc I, Bozic DZ, Vrecer F. Tableting process optimisation with the application of fuzzy models. International Journal of Pharmaceutics. 2010; 389(1-2):86-93. 